\title{
Determining the Self-Service Technology Adoption in Saudi Arabia: A Multi-Industry Approach
}

\author{
Abdul Rahim Abu Bakar ${ }^{1}$ \\ ${ }^{1}$ Marketing Department, College of Business Administration, Prince Sultan University, Riyadh, Saudi Arabia \\ Correspondence: Abdul Rahim Abu Bakar, Marketing Department, College of Business Administration, Prince \\ Sultan University, Riyadh, Saudi Arabia. E-mail: drrahimbakar@gmail.com or Aabubakar@fnm.psu.edu.sa
}

\author{
Received: February 14, $2014 \quad$ Accepted: March 10, $2014 \quad$ Online Published: May 21, 2014 \\ doi:10.5539/ijms.v6n3p111 URL: http://dx.doi.org/10.5539/ijms.v6n3p111
}

\begin{abstract}
This study investigates the adoption of self-service technologies (SST) among consumers in Saudi Arabia using the multi-industry approach. Unlike the majority of previous studies which either focuses on a specific industry or a specific SST, this study looks at SST adoption across multiple industries and across various SST platforms. In addition, it proposes a new construct - “consumers seek values" comprising of time convenience, ease of use, usefulness, secure/privacy, autonomy, service ubiquity and enjoyment adopting the Technology Acceptance Model (TAM) as the research framework. The model includes consumer demographic characteristics which represents the exogenous variable while consumer adoption of SST as the endogenous variable. Based from a mall-intercept technique, a final usable sample comprises of 400 respondents was collected in four major cities in Saudi Arabia. This represents an effective response rate of 44\%. The hypothesis was tested using SEM and WrapPLS to illustrate the relationship. The results showed that the proposed framework was significant.
\end{abstract}

Keywords: multi-industry, consumer seek values, self-service technologies, TAM, Saudi Arabia

\section{Introduction}

The current convergence of information and communication technology (ICT) is creating new opportunities. These include redeploying people, reconfiguring organizations, sharing information and investing in technologies. In addition "service-oriented thinking" activities are emerging at multiple organizational levels in business and it leverages technology in response to the growing need for greater business integration, flexibility, and agility. One of the technologies that have been utilized quite aggressively by firms in respond to the service-oriented thinking activities is self-service technologies (SST). These technologies are technological interfaces that enable customers to produce a service independent of direct service employee involvement (Meuter et al., 2000), i.e., person-to-technology service delivery (Dabholkar, 1994).

The importance of SSTs in the service environment has grown significantly over the last decade. Technology-based interactions are expected to become an increasingly important ingredient for long-term success in the delivery of services for industry such as retailing and hospitality (Bitner, Brown, \& Meuter, 2000) in the future. In this rapidly emerging, technologically oriented service concept, customers provide the service for themselves by utilizing technology with or without help from an employee of the service provider (Meuter, Ostrom, Roundtree, \& Bitner, 2000; Henderson, 2001).Strategically, the deployment of sophisticated SSTs in service encounters is expected to increase consumer satisfaction through improved service quality (Bitner et al., 2000; Parasuraman \& Grewal, 2000) while cutting costs at the same time (Weijters et al., 2007).

Nevertheless, although the proclaimed benefits of SSTs are enormous, relatively few institutions have publicly announced that the adopted SST has achieved its intended goals or objectives. The returns on technology infusion are not always satisfactory and are often substantive and not without risk (Jackson, Chow, \& Leitch, 1997) despite businesses having invested billions of dollars in these technologies (Lee \& Allaway, 2002). Other businesses also reported that despite the large amounts of capital invested in new customer service technology, the expected return on their investment has not been realized, either because employees do not always use the technology; executives contend that they see no linkage between their duties and what the technology does (Pijpers, Bebelmans, Heemstra, \& Montfort, 2001); or that it is often at times difficult to gauge users' acceptance when introducing new technology (James, Pirim, Boswell, Reithel, \& Barkhi, 2006). Although the use of SSTs in the service settings within the developed economies has seen an increasing level of acceptance by consumers, 
the same cannot be said in various countries throughout the world. Some economies have been very receptive to the new self-service technology, while others have been slow to accept and adopt it (Byun, 2007). With respect to the users' acceptance of SST in the developing economies, little is known about the consumer's adoption in the Arab world (Al-Ashban \& Burney, 2001). There are also limited researches that capture the factors that influenced customers' behavior to adopt or use SST in Saudi Arabia (Al-Somali et al., 2009).

Therefore, the aim of this paper is to explore the SST adoption in Saudi Arabia comprising of all sectors and all types of SST. The focus is to explore the consumer intention in SST adoption based on consumers seek values. The consumers seek values construct is a new construct proposed in this study that complements the TAM framework. The next section reviews the background of the study which is then followed by a section that discusses the theoretical approach and method used. The penultimate section presents the results of the study and in the last section, conclusions are drawn.

\section{Literature Review}

\subsection{Self-Service Technologies (SST)}

SST enables consumers to transact the business transactions without the involvement or interference of the service provider's staffs. Although the responsibility and burden of carrying out the service transaction are now passed to the consumer, SST is seen as a means of providing more touch points for consumers (Curran, Meuter, \& Surpenant, 2003). The authority or "job delegation" entrusted by the firm service provider to consumers to perform their own transactions enhanced the consumer decision making status where the consumer is now "involved" in the "production" or "execution" of the business transaction - instead of "passively" waiting on the receiving ends. As in the famous phrase "Customer is the King"- customers will decide what, when and how it wants the transactions to be conducted - at their own terms.

Scholars have noted that the consumer acceptance in SST is lagging and the number of consumers using these services has not increased to the degree expected (Flavian et al., 2004). In spite of the paucity of the SST utilization, researchers have yet to fully address the reasons for this resistance (Anguelov, Hilgert, \& Hogarth, 2004; Taft, 2007). Hence, the challenges for managers remain the same: how to determine the factors that enhance technology adoption? Therefore, to respond to these challenges, there is a need for an empirically relevant but also theoretically rigorous framework.

However, much of the existing research in SST adoption adopted the organizational perspective (Daniel, 1999) or a distribution channel perspective (e.g., Black et al., 2002; Mols, 2001). Meanwhile, previous researches on consumer adoption of SST tend to focus on a specific context or industry (e.g., banking). As far as we know, consumer SST adoption in a "multi-industry" context remained rather an uncharted territory. Meanwhile, although previous researches have link demographic attributes of potential adopters to be predictors of adoption (e.g., Al-Ashban \& Burney, 2001), scholars agree that there are other pertinent factors that determine a stronger predictor of the adoption decision. For instance, it is important to determine what is the motivation or expected value of consumers in using these technologies (Taft, 2007). Applying the SST solely focusing on the benefits of the providers (service organizations) such as cost reduction may lead to high supply chain effectiveness but the potential customer value opportunities may as well be ignored (Jonsson \& Gunnarsson, 2005). Therefore, understanding service user behavior and value perceptions is one of the fundamental requisites of SST development.

\subsection{Technology Acceptance Model (TAM)}

TAM was chosen to represent our research framework as it is a well-researched model that has proven accurate and effective in predicting and explaining the determinants of actual acceptance behavior of computer software, information technology and Internet-based information systems (Lu et al., 2003; Monsuwe et al., 2004; Ramayah \& Lo, 2007). TAM has been applied in many studies and has mostly received good results, although several studies have suggested that TAM still needs additional variables to modify it into an even stronger model (Legris et al., 2003; Lucas \& Spitler, 2000). One of the most salient criticisms of the TAM is the lack of acknowledgement of individual differences (Agarwal \& Prasad, 1999). Therefore, our study will include the consumer demographic characteristics in the research framework. Another criticism in TAM is that the model has no construct which represents an overall estimation of the adoption object (Kim et al., 2007). The relationship between consumer value and adoption intention has never been examined before (Kim et al., 2007) although there is a strong empirical support that consumer value affects perceptual intention to use (Sweeny, Soutar, \& Johnson, 1997). 
The missing 'variable' that is important to explain this 'equation' is the 'value' or needs expected from the customer of those particular self-service options. While this research makes an improvement to the existing TAM model, it still based its theory on the original model which makes this research highly generalizable and applicable to other industries, especially given Ong et al's. (2004) call to validate or examine previous results of TAM, specifically as it relates to differing technology, user populations, and organizational contexts. The following section describes the constructs proposed in this study which is the consumer seek values, consumer demographic characteristics, consumer intention to adopt SST and adoption of SST.

\subsection{Consumers Seek Values}

The basic assumption in examining the consumer intention to adopt SST is value fulfillment or attainment. The consumer expectations based on cognitive analysis are fundamental to the attainment of consumer seek value of SST products and services. Consumer decision whether to use or not use the self-service option is represented by their motive which is the desired 'end-states'. The consumer value is a subjective construct that is assessed by customers rather than by businesses; thus the value may vary among individuals (Huber et al., 2001; Zeithaml, Parasuraman, \& Berry, 1990). Despite of the differences in individual preferences specifically in the customers' needs and wants, there are some common needs and wants among them (Van Hagen, 2006). Among the common customer seek values are time and cost savings, control over the service delivery, reduced waiting time, a higher level of customization (Meuter \& Bitner, 1998), convenience of location (Kauffman \& Lally, 1994), fun or enjoyment from using the technology (Dabholkar, 1994, 1996), efficiency and flexibility (Bitner, Brown, \& Meuter, 2000).

We believe the cognitive analysis to identify the values or attributes expected from SST products and services (Taft, 2007) is important. Since such evaluations are more likely to emerge in the form of expectations in new or unfamiliar situations (Kim et al., 2007), cognitive analysis is particularly appropriate for our purposes. Therefore, the first hypothesis of this study is:

\section{Hypothesis 1: Consumers seek values influence the consumer intention to use SST.}

\subsubsection{Consumer Demographic Characteristics}

Consumer seek values differ from one consumer to another and this is influenced by various individual differences such as demographic factors. Demographic characteristics have long been a focus of innovation adoption literature, it is a primary predictors of adoption in which it influences the consumer's attitude and behavior intention in adopting SST (Rogers, 1995; Burke, 2002). A review of the research on consumer use of SSTs reveals a primary focus on individual differences (Parasuraman \& Colby, 2001) and on attitude models to predict intended behaviors (Curran, Meuter, \& Surprenant, 2003; Dabholkar \& Bagozzi, 2002). The impact of drivers of SST usage is not equal across different demographic groups (Chiu, Lin, \& Tang, 2005). Evidence for the importance of demographics in technology adoption has been recognized in a variety of studies (Morris \& Venkatesh, 2000; Venkatesh \& Morris, 2000; Venkatesh et al., 2003).

The most four major relevant variables known to have effect on the technology adoption are age, gender, education and income (Burke, 2002). People who adopt new technologies tend to be younger, male, and more educated and have a greater income than those who do not adopt it (Rogers, 1995; Sim \& Koi, 2002). Therefore, the following hypothesis is:

Hypothesis 2: There is a relationship between consumer demographic factors and consumers seek values.

\subsubsection{Consumer's SST Adoption}

Davis (1989) suggested that behavioral intention to use IT could well and accurately predicts actual IT use. Numerous technology acceptance studies favored this argument such as (e.g., So, Wong, \& Sculli, 2005; Venkatesh, Morris, Davis, \& Davis, 2003). Due to its convenience, most prior studies in SST adoption have focused only on behavioral intentions to adopt rather than the actual behavior (Curran et al., 2003; Dabholkar \& Bagozzi, 2002). Coherently, we have decided to prove this relationship empirically instead of completely relying on theoretical assumptions. In addition, our study is also in response to the "over-emphasis" of using consumer intention to represent actual adoption (Wang, Harris, \& Patterson, 2012). Therefore, the final hypothesis is as follows:

Hypothesis 3: Consumer behavior intention influence the consumer's SST adoption. 


\section{Data and Research Methodology}

\subsection{Data Collection}

Due to the unavailability of an established sampling frame and accessibility (there is no "complete" residential address in Saudi Arabia), survey based on convenience sampling was selected. The data collection process consists of enumerators asking questions to respondents face-to-face through a mall intercept. The main advantage of this method was that it helped the researcher to obtain complete and precise information (Zikmund, 2003). Item non response was also less likely to occur. Due to the country cultural influence, male and female enumerators were employed. 900 questionnaires were initially distributed to major commercial venues and public outlets that house self service facilities such as airports, shopping malls and banks in four major cities which are Riyadh, Dammam, Khobar and Jeddah. The data collection process lasted about eight weeks which starts in the first week of October 2012 and ended on the third week of November 2012.

Based on the laborious data collection effort, we received a feedback of 430 returned questionnaires. The returned questionnaires were later carefully examined for completeness. Twenty five (25) of those questionnaires were discarded because large sections of the questionnaires were incomplete. Five questionnaires were further discarded as the "reliability" of the responses was doubted. The total number of usable responses resulting from this process was finally 400 representing an effective response rate of 44 per cent. The response rate is quite good considering that the local culture do not normally response favorably to individuals asking questionnaires about their "personal behavior".

\subsection{Data Analyses}

Based on the descriptive statistics, the sample represents the general pattern of the population where it is dominated by male, relatively young and middle age, "educated" and employed by the government. Table 1 illustrates the descriptive characteristics of the consumer demographics.

Table 1. Respondent demographic statistics

\begin{tabular}{|c|c|c|c|c|}
\hline Characteristics & & Frequency & Total & Percentage \\
\hline \multirow[t]{2}{*}{ Gender } & Male & 269 & & 67.3 \\
\hline & Female & 131 & 400 & 32.8 \\
\hline \multirow[t]{7}{*}{ Age } & Below 18 & 25 & & 6.3 \\
\hline & $18-24$ & 61 & & 15.3 \\
\hline & $25-34$ & 177 & & 44.3 \\
\hline & $35-44$ & 84 & & 21.0 \\
\hline & $45-54$ & 40 & & 10.0 \\
\hline & $55-64$ & 11 & & 2.8 \\
\hline & Above 65 & 2 & 400 & 0.5 \\
\hline \multirow[t]{5}{*}{ Education } & Primary & 24 & & 6.0 \\
\hline & Secondary & 69 & & 17.3 \\
\hline & Certificate/Diploma & 117 & & 29.3 \\
\hline & Degree & 168 & & 42.0 \\
\hline & Postgraduate & 22 & 400 & 5.5 \\
\hline Monthly & Below 5000 & 111 & & 27.8 \\
\hline \multirow[t]{5}{*}{ Income (SAR) } & $5001-10000$ & 177 & & 44.3 \\
\hline & $10001-15000$ & 62 & & 15.5 \\
\hline & $15000-20000$ & 30 & & 7.5 \\
\hline & $20000-25000$ & 8 & & 2.0 \\
\hline & Above 25000 & 12 & 400 & 3.0 \\
\hline \multirow[t]{7}{*}{ Occupation } & Private & 88 & & 22.0 \\
\hline & Government & 216 & & 54.0 \\
\hline & Professionals & 26 & & 6.5 \\
\hline & Student & 35 & & 8.8 \\
\hline & Businessman & 12 & & 3.0 \\
\hline & Housewife & 18 & & 4.5 \\
\hline & Other & 5 & 400 & 1.3 \\
\hline
\end{tabular}

Coherently, we asked the respondents about their SST usage patterns. 61.5 percent of the respondents have either tried or is currently trying to use SST. Based from this segment, 44 per cent is a "hard core" user where 34 per 
cent is a repeat user and 10 per cent is a committed SST user. The remaining 17.5 per cent is trying to use or to get used of using SST. On the other hand, 38.5 percent of the respondents are currently a "non-user" with 14.3 per cent of this group contemplating or thinking of using SST. The findings of the "SST Adopter categories" demonstrate that the Saudi Arabian consumers have a relatively high rate of SST adoption despite the "stereotype" impression that Arabs prefer to have a personal or personnel attention from a service provider. Table 2 illustrates the SST usage behavior of SST adoption among the respondents.

Table 2. Respondent SST usage pattern

\begin{tabular}{lllll}
\hline Characteristics & & Frequency & Total & Percentage \\
\hline SST Status & Aware & 97 & & 24.3 \\
& Thinking to use & 57 & 14.3 \\
& Trying to use & 70 & 17.5 \\
& A repeated user & 136 & 34.0 \\
& Committed user & 40 & 400 & 10.0 \\
\hline SST Usage & Never & 11 & 2.8 \\
& Seldom & 35 & & 8.8 \\
& Occasionally & 75 & & 18.8 \\
& Often & 168 & 42.0 \\
& Always & 111 & 400 & 27.8 \\
\hline SST Experience & Less than 1 year & 43 & & 10.8 \\
(Years Used) & 1-2 years & 61 & & 15.3 \\
& 3-4 years & 116 & & 29.0 \\
& More than 4 years & 162 & 40.5 \\
& Never use & 18 & 400 & 4.5 \\
\hline
\end{tabular}

All of the measures were adopted or adapted from established scales. Nevertheless, all the scales were subjected to the same rigorous analysis, where the items were subjected to refinement and various aspects of reliability were evaluated prior to the data analysis (Churchill 1979, Anderson \& Gerbing, 1988). The subsequent paragraph elaborates how the measurements were assessed for their reliability, dimensionality and construct validity using established procedures. We conducted principal component factor analysis on all the variables using VARIMAX rotation. The following tables showed the results of all the factor analysis conducted on the consumers seek values, consumer intention and SST adoption construct adopted in this study.

Table 3. Results of factor analysis for consumers seek values

\begin{tabular}{ll}
\hline Factor Items & Item Loading \\
\hline Factor 1 - Autonomy (Cronbach $\alpha=0.849 /$ Variance=10.416\%) & 0.745 \\
I want to avoid problems by doing on my own & 0.733 \\
I want to be autonomous in taking care of my matters & 0.728 \\
I want to make my own choices and decisions & 0.726 \\
SST lets the customer be in charge & 0.667 \\
I want to handle my needs on my own & 0.653 \\
SST gives me control & \\
Factor 2 - Effectiveness (Cronbach $\alpha=0.877 /$ Variance= $=10.192 \%)$ & 0.826 \\
SSTs is in customer's best interest & 0.823 \\
I have complete satisfactory SSTs experience & 0.820 \\
SSTs process free of errors & 0.788 \\
SSTs is reliable & 0.710 \\
SSTs provide all my needs & \\
Factor 3 - Enjoyment (Cronbach $\alpha=0.971 /$ Variance=10.054\%) & \\
Using SSTs is pleasant & 0.823 \\
Using SSTs is fun & 0.793 \\
It is exciting to use SSTs & 0.792 \\
Using SSTs is pleasurable & 0.789 \\
Using SSTs is enjoyable & 0.697 \\
\hline
\end{tabular}




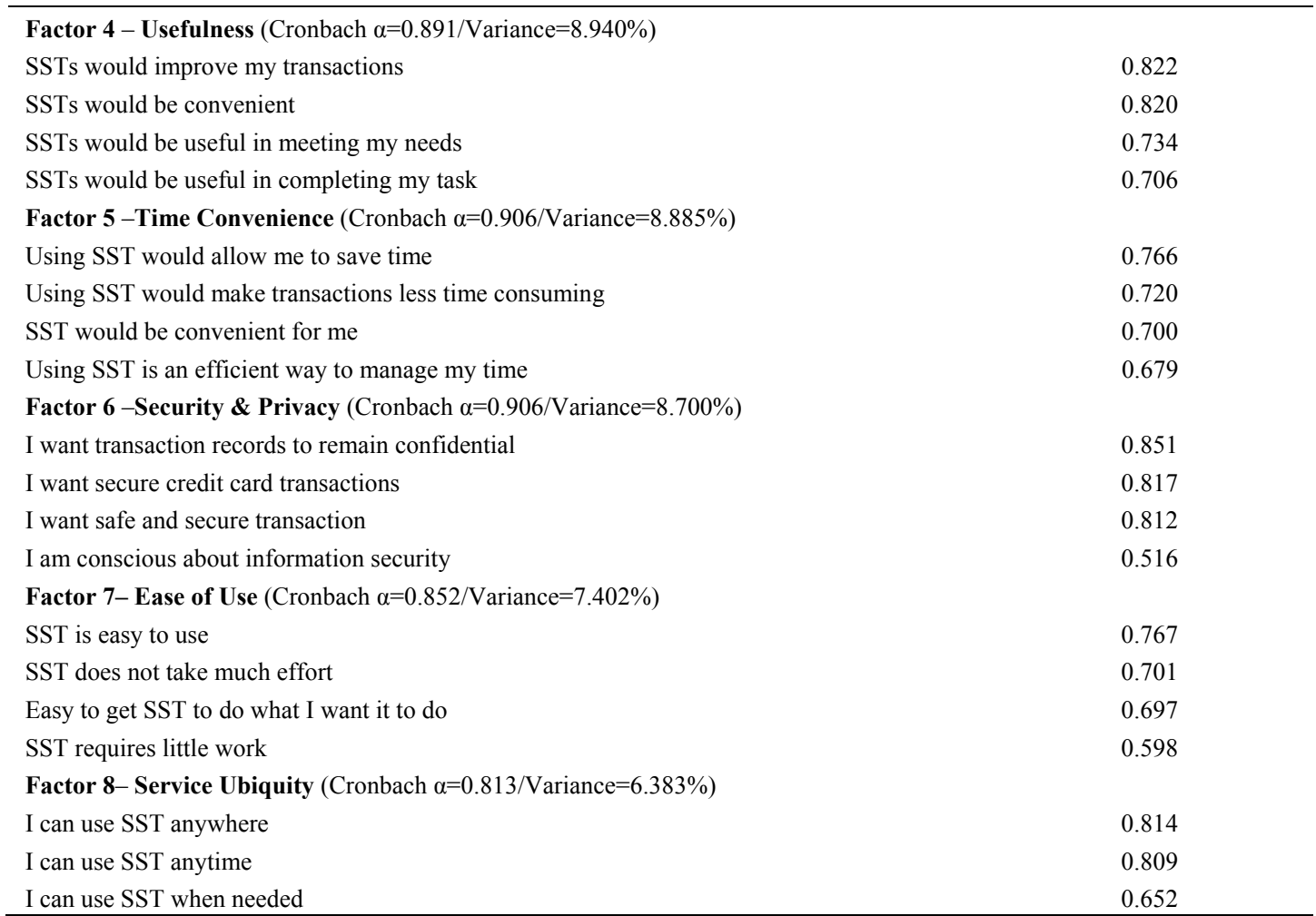

Note. *(All the loadings $<.45$ is suppressed).

Table 4. Results of factor analysis for consumer intention \& SST adoption

\begin{tabular}{ll}
\hline Factor Items & Item Loading \\
\hline Factor 1 - Consumer Intention (Cronbach $\alpha=0.873 /$ Variance=72.436\%) & \\
I will continue to use self-service technologies in the near future & 0.864 \\
I am willing to use self-service technologies in future & 0.858 \\
I intend to use self-service technologies in the near future & 0.854 \\
I am likely to use self-service technologies in the near future & 0.828 \\
Factor 2 - SST Adoption (Cronbach $\alpha=0.619 /$ Variance=59.509\%) & 0.809 \\
SST is definitely for me & 0.753 \\
If I had to do any transaction, I would still use self-service technology & 0.750 \\
How often do you use self-service technologies? & \\
\hline
\end{tabular}

Note. *(All the loadings $<.45$ is suppressed).

The results of the principal component analysis showed that all the proposed constructs and dimensions adopted in this study are universally distinct and unique. All the scales show good reliability with Cronbach's alphas exceeding the recommended value of 0.70 as suggested by Nunnally (1978). In coherent with the rigorous procedures proposed and adopted in previous studies, the following purification process involve testing the construct dimensionality through Confirmatory Factor Analysis (CFA). The following sections will discuss the results of the analysis using Structural Equation Modeling (SEM) using AMOS version 19.0.

The proposed constructs were then subjected to the CFA. This includes convergent validity and discriminant validity under the principles of SEM. Subsequently, the testing of the structural model served as a confirmatory assessment of the nomological validity. The initial measurement model for the consumers seek values did not result to a satisfactory score. The goodness-of-fit indexes were less that the recommended scores. Though all regression weights in the model were significant, model fit still was not acceptable and the modification indices showed many values that were very high. Therefore, a decision was made to revise the initial model based on the recommended modification index. The revised measurement model depicted acceptable scores where the goodness-of-fit indexes exceed the recommended scores as suggested by Lichtenstein et al. (1992). Figure 1 illustrates the CFA for consumers seek values. 


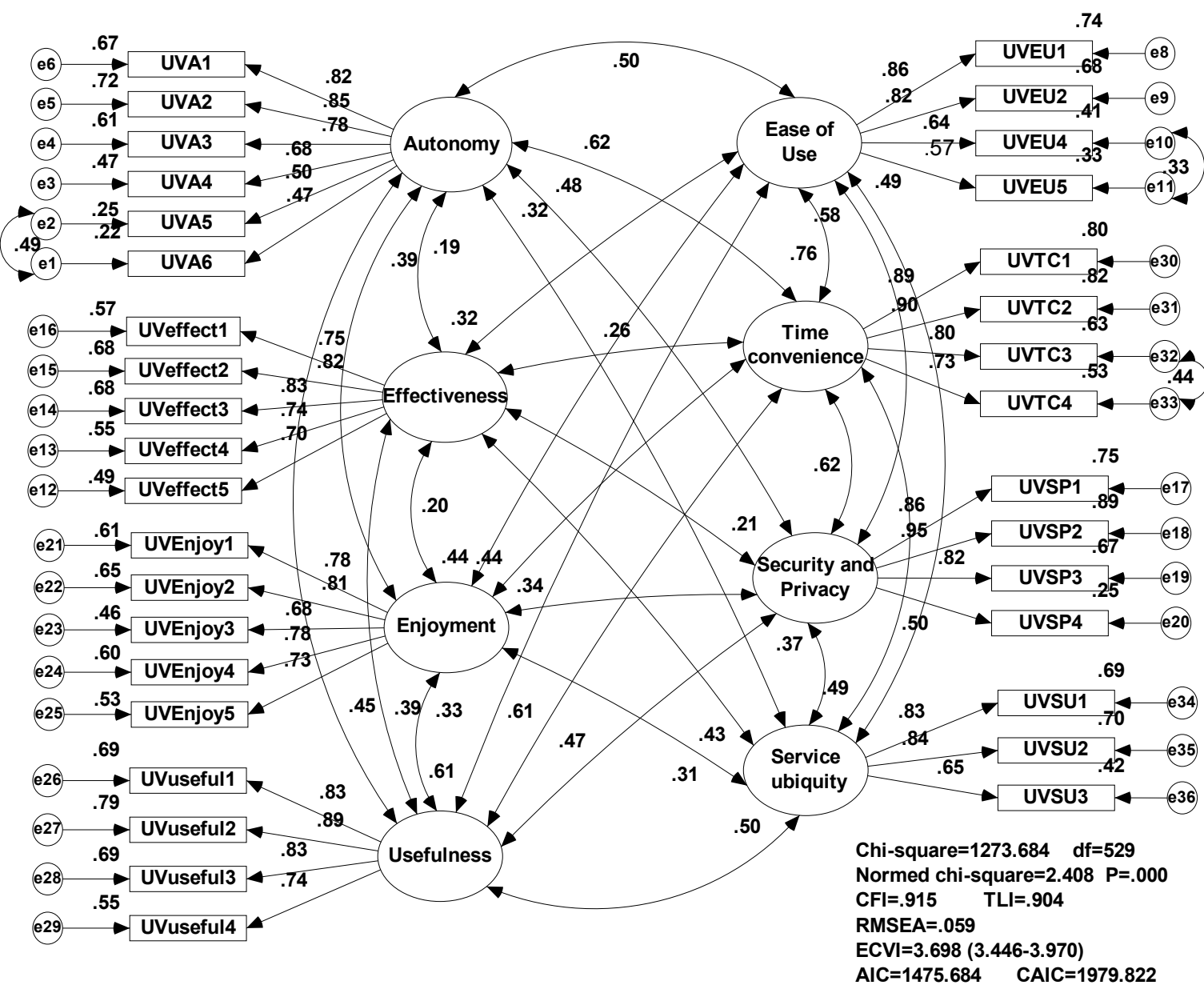

Figure 1. CFA results for consumers seek values

As depicted in Figure 1, with the exception of effectiveness dimension, all the loading factors for the individual measurements were above the suggested guidelines for the measurement item. Subsequently, the measurements for each factor were analyzed based on summated score of all the items representing the dimension. The result of the analysis based on the summated score is much easier to "illustrate" or to figure out the interrelationship between the dimensions as the output is much simplified. The analyses showed the higher-order or second-order relationship of the dimensions of consumers seek values. Figure 2 demonstrates the summated scores of consumers seek values.

The CFA analysis for the summated consumers seek values demonstrated that all the remaining seven dimensions are acceptable. Time convenience seems to have the highest factor loading followed by ease of use. Next are usefulness, secure/privacy, autonomy, service ubiquity and enjoyment. While a lot of innovation studies have identified enjoyment as an important factor in adopting a technology, the results showed here illustrates an important point. For SST, time convenience, ease of use, usefulness and secure / privacy are the important dimensions identified in the adoption of SST across all sectors. 


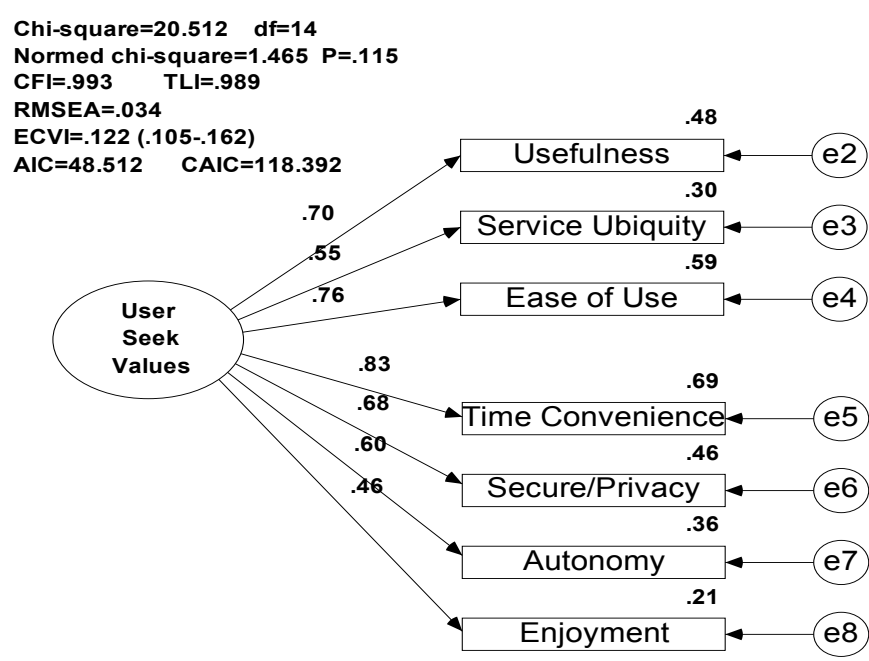

Figure 2. Summated score of consumers seek values

The CFA results confirmed that all the four items in the behavior intention and three items in SST adoption is valid (convergent and discriminant validity) based on the original model (without any revision to the model). The two constructs meet the recommended threshold of the goodness-of-fit indexes suggested by previous scholars in this study. As for the SST adoption construct, the dimension has only 3 items. As constructs with only two or three items are under- or just-identified, no model fit indices can be obtained (Ping Jr., 2004). Therefore, the measurement model for SST adoption is just-identification-meaning it does not have the full information of the maximum likelihood indices. Figures 3 and 4 illustrate the results of the CFA of the two constructs.

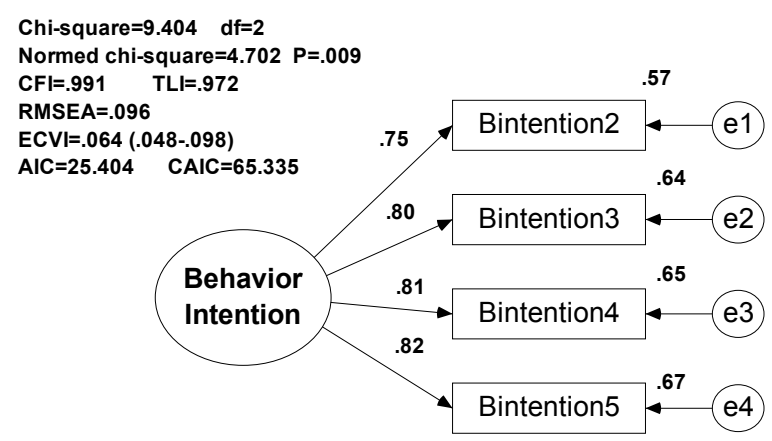

Figure 3. Results of CFA for behavior intention

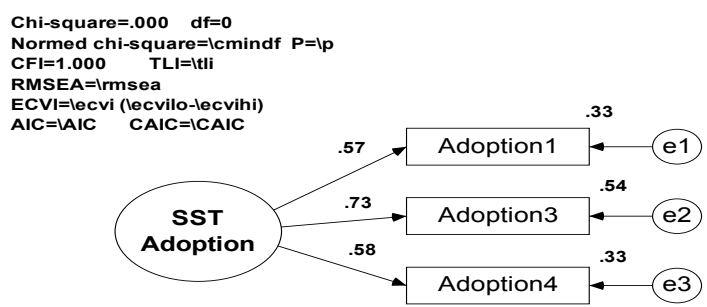

Figure 4. CFA for SST adoption

The CFA results showed that all the constructs and its dimensions fulfill the recommended threshold level in terms of goodness-of-fit. Table 5 shows the goodness-of-fit indexes for all the constructs adopted in this study. 
Subsequently, further analysis of SEM was done to test the proposed hypotheses and relationship in this study. The result of the demographic variables: income, age, education, gender and occupation showed that gender and occupation have low coefficients at -0.22 and 0.2 respectively, suggesting that the items is removed from the model. The revised structural model fit the data very well and surpassed the recommended threshold level of goodness-of-fit indexes. All measures of model fit indicated that the model fits the data well.

Table 5. All constructs-model fit indices

\begin{tabular}{lllllccc}
\hline Construct & CMIN/DF & GFI & AGFI & CFI & NFI & RMSEA & PCLOSE \\
\hline Consumers Seek Values & 1.465 & .986 & .973 & .993 & .978 & .034 & .784 \\
Behavior Intention & 4.702 & .989 & .943 & .991 & .988 & .096 & .079 \\
SST adoption & & \multicolumn{7}{c}{ Measurement model is just-identification. } \\
\hline
\end{tabular}

The two main structural equation analysis have successfully tested the proposed relationship between consumer demographic towards consumers seek values, consumers seek values influencing behavior intention and finally the relationship of behavior intention towards SST adoption. Table 6 summarizes the findings of the SEM analysis while figure 5 illustrates the results of the SEM analysis of the whole constructs using WrapPLS.

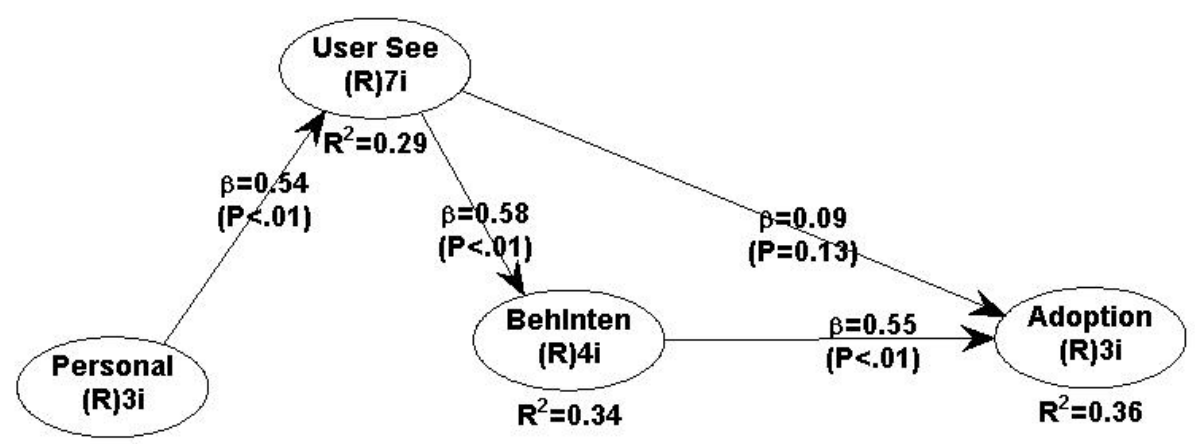

Figure 5. SEM results of research framework

Table 6. Regression weights and significance of paths: total sample

\begin{tabular}{lllll}
\hline Hypothesis & Paths & $\begin{array}{l}\text { Standardized } \\
\text { Estimate }\end{array}$ & $\begin{array}{l}\text { Standard } \\
\text { Error }\end{array}$ & Sig. \\
\hline $\mathrm{H}: 1$ & Consumers Seek Value $\longrightarrow$ Behaviour intention & 0.584 & 0.042 & $* * *$ \\
$\mathrm{H}: 2$ & Demographic $\longrightarrow$ User seek value & 0.534 & 0.049 & $* * *$ \\
$\mathrm{H}: 3$ & Behaviour intention $\longrightarrow$ SST adoption & 0.545 & 0.063 & $* * *$ \\
$\mathrm{H}_{\mathrm{A}}$ & Consumers Seek Value $\longrightarrow$ SST adoption & 0.088 & 0.078 & 0.131 \\
\hline
\end{tabular}

Note. $* * \mathrm{p} \leq 0.01 ; * * * \mathrm{p} \leq 0.001$.

\section{Discussions and Conclusions}

\subsection{Discussions}

Our study provides support that there are proliferations of values that consumers seek in adopting a particular form of technology. Based from our findings, it is evident that there are "significant" values which were not covered or investigated in previous studies. For instance, our findings demonstrated that although "Ease of Use" and "Usefulness" continue to be an important element or value seek by customers in adopting SST; "Time convenience" is the most dominant value. Therefore, while it is important that the service provider's SST is easy to use and offers numerous benefits, it is of paramount importance that it should provide a time convenience-meaning that it gives a time advantage over personal or current service operations. While the 
findings of the importance of time convenience value seem predictable, it demonstrates that in deciding between the choices of personal service over SST, the ability of the SST facility to offer time advantage is the determining factor.

The findings of time convenience or speed in the consumer intention to adopt SST facilities demonstrates the universality of the consumers seek values. This is an interesting discovery since Saudi Arabia is a country which has the traits of a polychronic time culture (Hall, 1976). A culture which is deeply steeped in tradition and relationships rather than in executing tasks. We argue that the "contradiction" in the Saudi Arabian consumers seek values and their polychronic time culture illustrates that "these SST adopters" may not share the traditional views of their local cultures. A plausible example of this phenomenon could be due to the nature of their occupation. Based from the descriptive characteristics, it can be observed that the majority of the respondents are "middle level" managers who either work for the government, private or running their own business. In general, these individuals are normally busy running their daily occupational duties in addition to doing their own "chores". Therefore, their appreciation of time is more distinct and different than their counter parts in other job positions. On the same note, this "segment" represents the same characteristics of the users of SSTs on a global perspective.

With regards to the two "established" consumers seek values identified in this study which are "Ease of Use" and "Usefulness", the findings demonstrate that the two values were consistent to be a significant factor. Our study mirrors the results of previous scholars which are ease of use (Curran \& Meuter, 2005; Timmor \& Rymon, 2007) and usefulness (Lin et al., 2007; Walker \& Johnson, 2006) that were found to be among the main factors of consumer intention to adopt SST. This shows that the constructs are empirically reliable and valid where it explains the various types of technology adoption in numerous economies (countries) and in different context (multiple industries).

An equally important user seeks value that influence customer intention to adopt SST is that the facility is secure and ensures customer privacy. We believe this fourth value identifies by the customer "sums up" the "main" core values seen as important in their consideration of adopting SST. "Easy to use" SST facilities that are "useful" are the "pillars" that deliver the ultimate value of "time convenience" to the user. However, to reduce potential risk and encourage trial, the overall "foundation" of the SST facilities is it must be secure and ensures privacy. Our argument is based on Curran and Meuter (2005) study which found that the adoption of online banking was more influenced by consumers' perceptions of risk, than by their perceptions of its usefulness or ease of use.

Bateson (1985) was one of the earlier scholars who found that self-service consumers preferred increased control in their transaction. A stream of researchers later showed that control was indeed an important aspect of self-service adoption although it did not received the same attention as the other determinants such as ease of use and usefulness (Dabolkar, 1996; Hoffman \& Novak, 1996). Wang, Harris and Patterson (2012) argued that the purpose of introducing self-service is not to entirely replace the traditional personal service, but rather to provide a choice and a sense of control, and thereby enhance the overall customer experience (Salomann et al., 2006). Therefore, the "final" users seek value of security and privacy act as the foundation for these three users seek values. These prime values which are time convenience, ease of use, usefulness and secure/privacy are "distinct" values that the users seek in SST facilities. Therefore, business or service providers have to ensure that these values are met and "visible" or "tangible" in place before any consumer would consider trying or adopting SST.

Subsequently, the next user seek values such as autonomy, service ubiquity and enjoyment are values which are "complimentary" that users look for in their effort to adopt SST. These values are not "prerequisite" values that users aspire when contemplating to use SST. However, these values are seen as "auxiliary" or "augmenting" what personal or current counter service could not offer over SST. Hence, it enhances the "desire" to use SST over current methods of service delivery. For instance, by conducting their own transactions over SST, it enhances the value of autonomy to determine their own outcome. The autonomy value builds upon the control value where a user that is able to control his or her task "expected" that he has the autonomy to determine how the transaction should be carry out without the interference of a service provider. Consequently, their ability to conduct the transaction autonomously is extended by the service ubiquity which enables the user to carry out their tasks anytime and anywhere. Coherently, carrying out these generally "mundane" tasks is alleviated since it is "fun" to do it yourself. The inter-relation or correlations of consumers seek values is illuminated through the confirmatory factor analysis where these values "covariate" with each other.

Subsequently, consumer seek value of service ubiquity which reflects that SST can be conducted anywhere and anytime can be argued as part of a subset of the usefulness value. Based on our argument, the usefulness construct could actually be a higher order construct where values such as service ubiquity and effectiveness form 
the lower order values. Finally, the consumers seek values of enjoyment has been proved in the past as an important factor in influencing consumer intention to adopt SST. Curran and Meuter (2007) and Weijters et al. (2007) are among the recent researchers that identified enjoyment as a factor that influence consumer intention to adopt SST. Their studies corroborate a "consistent" finding from previous study for instance from Dabholkar, Bobbitt and Lee (2003) that proposed that customers also enjoy the SST interaction. Although our research finding is consistent with the result from previous studies, the enjoyment value is the "least" important value seeks by the users of SST.

\subsection{Summary and Conclusions}

Based on our existing knowledge this study is one of the earliest attempts to investigate consumer adoption of SST across multiple industries and across various SST platforms. As we have pointed out earlier, a majority of studies conducted previously where either focuses on a specific industry or a specific SST. This specific focus has contributed to the inconsistencies of the findings of the SST adoption studies in addition to the external validity issues. This study therefore rectifies the limitations of the current literatures by having a comprehensive representation of the service industry and meets the requirements of external validity which qualifies for generalization of the findings.

Second, we argued that although TAM receives widespread acceptance, it "misses" the true "reason" of adoption as well as being too simplistic. Curran and Meuter (2005) and Gefen et al. (2003) are among the scholars that argued TAM could not explain fully SST adoption. We explained that customer value has become increasingly important to marketing researchers in their studies, emerging as a key determinant of consumer decision-making and behavior (Sheth, Newman, \& Gross, 1991; Bolton \& Drew, 1991). This study consequently responds to the call by Zu, Sangwan and $\mathrm{Lu}$ (2010) calls for an in-depth study of the "value driven" triadic relationship among consumer, value and behavior. Therefore, the findings of this study contribute to the technology adoption literature by improving the TAM model through the addition of an important construct.

Another contribution of this study is proving the relationship between customer intention to adopt SST and the actual adoption of SST. As highlighted in the research problem, most prior studies have focused on behavioral intentions rather than actual behavior (Curran et al., 2003; Dabholkar \& Bagozzi, 2002). The risk of focusing on behavioral intentions instead of actual behavior is that intentions do not always lead to action. Meuter et al. (2005) has called for researchers to carry out SST adoption research to go beyond the emphasis on attitudes and intentions and focus on the actual adoption behavior. Hence, the findings of our study provide the much needed evidence of the proposed relationship which makes our model more relevant to the real world.

Finally, with respect to the users' acceptance of SST in the developing economies, little is known about the consumer's adoption in the Arab world (Al-Ashban et al., 2001). Verhage, Yavas, and Green (1990) warn that "global marketers need to be very cautious in accepting theories or techniques that are proven to be successful in their home markets". With limited researches that capture the factors that influenced customers' behaviour to adopt or use SST in Saudi Arabia (Al-Somali et al., 2009), this research makes a significant contribution in this context.

\section{References}

Agarwal, R., \& Prasad, J. (1999). Are individual differences germane to the acceptance of new information technology? Decision Sciences, 30(2), 361-391. http://dx.doi.org/10.1111/j.1540-5915.1999.tb01614.x

Al-Ashban, A. A., \& Burney, M. A. (2001). Customer adoption of tele-banking technology: the case of Saudi Arabia. International Journal of Banking Marketing, 19(5), 191-200. http://dx.doi.org/10.1108/02652320110399683

Al-Somali, S. A., Gholami, R., \& Clegg, B. (2009). An investigation into the acceptance of online banking in Saudi Arabia. Technovation, 29(2), 130-141. http://dx.doi.org/10.1016/j.technovation.2008.07.004

Anderson, J. C., \& Gerbing, D. W. (1988). Structural equation modeling in practice: A review and recommended $\begin{array}{lllll}\text { two-step approach. } & \text { Psychological }\end{array}$ http://dx.doi.org/10.1037/0033-2909.103.3.411

Anguelov, C. E., Hilgert, M. A., \& Hogarth, J. M. (2004). U.S. consumers and electronic banking, 1995-2003. The Federal Reserve Board.

Bateson, J. E. G. (1985). Perceived control and the service encounter, in the service encounter: Managing employee/customer interaction in service businesses. In J. A. Czepiel, M. R. Solomon, \& C. F. Surprenant (Eds.), Lexington Books (pp. 67-82). Lexington: Mass. 
Bitner M., Brown, S. W., \& Meuter, M. L. (2000). Technology infusion in service encounters. Journal of the Academy of Marketing Science, 28(10), 138-149. http://dx.doi.org/10.1177/0092070300281013

Bolton, R. N., \& Drew, J. H. (1991). A multi-stage model of consumers' assessments of service quality and value. Journal of Consumer Research, 17(4), 375-384. http://dx.doi.org/10.1086/208564

Burke, R. R. (2002). Technology and the customer interface: what consumers want in the physical and virtual store. Journal of the Academy of Marketing Science, 30(4), 411-432. http://dx.doi.org/10.1177/009207002236914

Byun, S. (2007). The value of technology in service encounters: exploring consumer perceptions of biometric access at automatic teller machines. Unpublished $\mathrm{PhD}$ Thesis, Purdue University West Lafayette, Indiana.

Chiu, Y. B., Lin, C. P., \& Tang, L. L. (2005). Gender differs: assessing a model of online purchase intentions in e-tailing service. International Journal of Service Industry Management, 16(5), 416-435. http://dx.doi.org/10.1108/09564230510625741

Churchill, G. A. Jr. (1979). A paradigm for developing better measures of marketing constructs. Journal of Marketing Research, 16(February), 64-73. http://dx.doi.org/10.2307/3150876

Curran, J. M., \& Meuter, M. L. (2005). Self service technology adoption: Comparing three technologies. Journal of Services Marketing, 19(2), 103-114. http://dx.doi.org/10.1108/08876040510591411

Curran, J. M., Meuter, M. L., \& Surprenant, C. F. (2003). Intentions to use self-service technologies: a confluence of multiple attitudes. Journal of Service Research, 5(3), 209-224. http://dx.doi.org/10.1177/1094670502238916

Dabholkar, P. A. (1994). Technology-based self-service delivery: a classification scheme for developing marketing strategies. Advances in Services Marketing and Management, 3, 241-271. http://dx.doi.org/10.1016/S1067-5671(94)03021-9

Dabholkar, P. A. (1996). Consumer evaluations of new technology-based self-service options: an investigation of alternative models of service quality. International Journal of Research in Marketing, 13, 29-51. http://dx.doi.org/10.1016/0167-8116(95)00027-5

Dabholkar, P. A., \& Bagozzi, R. P. (2002). An attitudinal model of technology-based self-service: moderating effects of consumer traits and situational factors. Journal of the Academy of Marketing Science, 30(3), 184-201. http://dx.doi.org/10.1177/0092070302303001

Dabholkar, P. A., Michelle, L., \& Bobbitt, L. E. U. (2003). Understanding consumer motivation and behavior related to self-scanning in retailing: Implications for strategy and research on technology-based self-service. International Journal of Service Industry Management, 14(1), 59-95. http://dx.doi.org/10.1108/09564230310465994

Davis, F. (1989). Perceived usefulness, perceived ease of use, and user acceptance of information technology. MIS Quarterly, September, 319-340. http://dx.doi.org/10.2307/249008

Davis, F. D., Bagozzi, R. P., \& Warshaw, P. R. (1989). User acceptance of computer technology: a comparison of two theoretical models. Management Science, 35, 982-1003. http://dx.doi.org/10.1287/mnsc.35.8.982

Flavian, C., Torres, E., \& Guinaliu, M. (2004). Corporate image measurement: A further problem for the tangibilization of Internet banking services. The International Journal of Bank Marketing, 22(4/5), 366-381. http://dx.doi.org/10.1108/02652320410549665

Gefen, D., Karahanna, E., \& Straub, D. W. (2003). Inexperience and experience with online store: The importance of TAM and trust. IEEE Transactions on Engineering Management, 50(3), 307-321. http://dx.doi.org/10.1109/TEM.2003.817277

Hall, E. T. (1976). Beyond Culture. New York: Doubleday.

Henderson, T. P. (2001). Multi-channel retailers increasingly rely on internet-based kiosks to bridge gap between channels. Stores, October.

Hoffman, D., \& Novak, T. (1996). Marketing in hypermedia computer-mediated environments: conceptual foundations. Journal of Marketing, 60, 50-68. http://dx.doi.org/10.2307/1251841

Huber, F., Herrmann, A., \& Morgan, R. E. (2001). Gaining competitive advantage through customer value oriented management. Journal of Consumer Marketing, 18(1), 41-53. http://dx.doi.org/10.1108/07363760110365796 
Jackson, C. M., Chow, S., \& Leitch, R. A. (1997). Toward an understanding of the behavioral intention to use an information system. Decision 357-390. http://dx.doi.org/10.1111/j.1540-5915.1997.tb01315.x

James, T., Pirim, T., Boswell, K., Reithel, B., \& Barkhi, R. (2006). Determining the intention to use biometric devices: An application and extension of the technology acceptance model. Journal of End User Computing, 18(3), 1-24. http://dx.doi.org/10.4018/joeuc.2006070101

Jonsson, S., \& Gunnarsson, C. (2005). Internet technology to achieve supply chain performance. Business Process Management Journal, 11(4), 403-417. http://dx.doi.org/10.1108/14637150510609426

Kauffman, R. J., \& Lally, L. (1994). A value platform analysis perspective on customer access information technology. Decision $\quad$ Sciences, 25(September-December), http://dx.doi.org/10.1111/j.1540-5915.1994.tb01869.x

Kim, H. W., Chan, H. C., \& Gupta, S. (2007). Value-based adoption of mobile Internet: An empirical investigation. Decision Support Systems, 43, 111-126. http://dx.doi.org/10.1016/j.dss.2005.05.009

Lee, J. K., \& Allaway, A. (2002). Effects of personal control on adoption of self-service technology innovations. Journal of Services Marketing, 16(6), 553-572. http://dx.doi.org/10.1108/08876040210443418

Legris, P., Ingham, J., \& Collerette, P. (2003). Why do people use information technology? A critical review of the technology acceptance model. Information and Management, 40, 191-204. http://dx.doi.org/10.1016/S0378-7206(01)00143-4

Lichtenstein, D., Ridgway, N., \& Retemyer, R. (1992). Price perceptions and consumer shopping behavior: a field study. Journal of Marketing Research, 30(May), 234-245.

Liebermann, Y., \& Stashevsky, S. (2002). Perceived risks as barriers to internet and e-commerce usage. Qualitative Market Research: An International Journal, 5(4), 291-300. http://dx.doi.org/10.1108/13522750210443245

Lin, C. H., Shih, H. Y., \& Sher, P. J. (2007). Integrating technology readiness into technology acceptance: The TRAM model. Psychology \& Marketing, 24(7), 641-657. http://dx.doi.org/10.1002/mar.20177

Lu, J. C. S., Liu, C., \& Yao, J. C. (2003). Technical acceptance model for wireless internet. Internet Research, 73(3), 207-223.

Lucas, Jr. H. C., \& Spitler, V. K. (2000). Implementation in a world of workstations and networks. Information \& Management, 38(2), 119-128. http://dx.doi.org/10.1016/S0378-7206(00)00059-8

Meuter, M. L., \& Bitner, M. J. (1998). Self-service technologies: extending service frameworks and identifying issues for research. In Dhruv Grewal \& Connie Pechmann (Eds.), Marketing Theory and Applications (pp. 12-19). Chicago, Illinois: American Marketing Association.

Meuter, M. L., Ostrom, A. L., Roundtree, R. I., \& Bitner, M. J. (2000). Self-service technologies: understanding customer satisfaction with technology-based service encounters. Journal of Marketing, 64(3), 50. http://dx.doi.org/10.1509/jmkg.64.3.50.18024

Mols, N. P. (2001). Organizing for the effective introduction of new distribution channels in retail banking. European Journal of Marketing, 35(5/6), 661-686. http://dx.doi.org/10.1108/03090560110388150

Monsuwe, T. P. Y., Dellart, B. G. C., \& de Ruyter, K. (2004). What drives consumers to shop online? A literature review. International Journal of Service Industry Management, 15(1), 102-121. http://dx.doi.org/10.1108/09564230410523358

Morris, M. G., \& Venkatesh, V. (2000). Age differences in technology adoption decisions: implications for a $\begin{array}{lllll}\text { changing } \quad \text { Porkforce. } & \text { Personnel 375-403. }\end{array}$ http://dx.doi.org/10.1111/j.1744-6570.2000.tb00206.x

Nunnally, J. C. (1978). Psychometric theory (2nd ed.). New York: McGraw-Hill.

Ong, C. S., Lai, J. Y., \& Wang, Y. S. (2004). Factors affecting engineers acceptance of asynchronous e-learning systems in high-tech companies. Information \& Management, 41(6), 765. http://dx.doi.org/10.1016/j.im.2003.08.012

Parasuraman, A., \& Colby, C. L. (2001). Techno-ready marketing. New York: The Free Press. 
Parasuraman, A., \& Grewal, D. (2000). The impact of technology on the quality-value loyalty chain: A research agenda. Journal of the Academy of Marketing Science, 28(1), 68-174. http://dx.doi.org/10.1177/0092070300281015

Pijpers, G. G. M., Bemelmans, T. M. A., Heemstra, F. J., \& van Montfort, K. A. G. M. (2001). Senior executives' use of information technology. Information and Software Technology, 43, 959-971. http://dx.doi.org/10.1016/S0950-5849(01)00197-5

Ping, Jr. R. (2004). On assuring valid measures for theoretical models using survey data. Journal of Business Research, 57(2), 125-141. http://dx.doi.org/10.1016/S0148-2963(01)00297-1

Ramayah, T., \& Lo, M. Y. (2007). Impact of shared beliefs on "perceived usefulness" and "ease of use" in the implementation of an enterprise resource planning system. Management Research News, 30(6), 420-431. http://dx.doi.org/10.1108/01409170710751917

Rogers, E. M. (1995). Diffusion of innovations. New York: The Free Press.

Salomann, H., \& Kolbe, L. (2006). Self-services in customer relationships: balancing high-tech and high-touch today and tomorrow. E-Service Journal, 4(2), 65. http://dx.doi.org/10.2979/ESJ.2006.4.2.65

Sheth, J. N., Newman, B. I., \& Gross, B. L. (1991). Why we buy what we buy: A theory of consumption values. Journal of Business Research, 22(2), 159-170. http://dx.doi.org/10.1016/0148-2963(91)90050-8

Sim, L. L., \& Koi, S. M. (2002). Singapore's internet shoppers and their impact on traditional shopping patterns. Journal of Retailing and Consumer Services, 9(2), 115-124. http://dx.doi.org/10.1016/S0969-6989(01)00029-7

So, W. C., Wong, D., \& Sculli, D. (2005). Factors affecting intentions to purchase via the internet. Industrial Management \& Data Systems, 105(9), 1225-1244. http://dx.doi.org/10.1108/02635570510633275

Sweeney, J. C., Soutar, G. N., \& Johnson, L. W. (1997). Retail service quality and perceived value. Journal of Retailing and Consumer Services, 4(1). http://dx.doi.org/10.1016/S0969-6989(96)00017-3

Taft, J. (2007). An examination of the antecedents of electronic banking technology acceptance and use. Unpublished $\mathrm{PhD}$ Thesis. Touro University International

Timmor, Y., \& Rymon, T. (2007). To do or not to do-the dilemma of based technology service improvement. Journal of Services Marketing, 21(2), 99-111. http://dx.doi.org/10.1108/08876040710737868

Venkatesh, V., \& Davis, F. D. (2000). A theoretical extension of the Technology Acceptance Model: Four $\begin{array}{llll}\text { longitudinal field } & \text { studies. }\end{array}$ http://dx.doi.org/10.1287/mnsc.46.2.186.11926

Venkatesh, V., Morris, M. G., Davis, G. B., \& Davis, F. D. (2003). User acceptance of information technology: toward a unified view. MIS Quarterly, 27(3).

Verhage, B. J., Yavas, U., \& Green, R. T. (1990). Perceived Risk: A Cross-Cultural phenomenon? International Journal of Research in Marketing, 7(4), 297-303. http://dx.doi.org/10.1016/0167-8116(90)90007-A

Walker, R., \& Johnson, L. (2006). Why consumers use and do not use technology-enabled services. Journal of Services Marketing, 20(2), 125-35. http://dx.doi.org/10.1108/08876040610657057

Wang, C., Harris, J., \& Patterson, P. G. (2012). Customer choice of self-service technology: the roles of situational influences and past experience. Journal of Service Management, 23(1), 54-78. http://dx.doi.org/10.1108/09564231211208970

Weijters, B., Rangarajan, D., Falk, T., \& Schillewaert, N. (2007). Determinants and outcomes of customer use of self-service technology in a retail setting. Journal of Service Research, 10(1), 3-21. http://dx.doi.org/10.1177/1094670507302990

Zeithaml, V. A., Parasuraman, A., \& Berry, L. L. (1990). Delivering quality service: Balancing customer perceptions and expectations. New York: Free Press.

Zhu, G., Ma, L., Sangwan, S., \& Lu, T. J. (2010). Consumer adoption model and empirical research based on social cognitive theory. Nankai Business Review, 13(3), 12-21.

Zikmund. (2003). Business Research Methods. Thomson/South-Western. 


\section{Copyrights}

Copyright for this article is retained by the author(s), with first publication rights granted to the journal.

This is an open-access article distributed under the terms and conditions of the Creative Commons Attribution license (http://creativecommons.org/licenses/by/3.0/). 